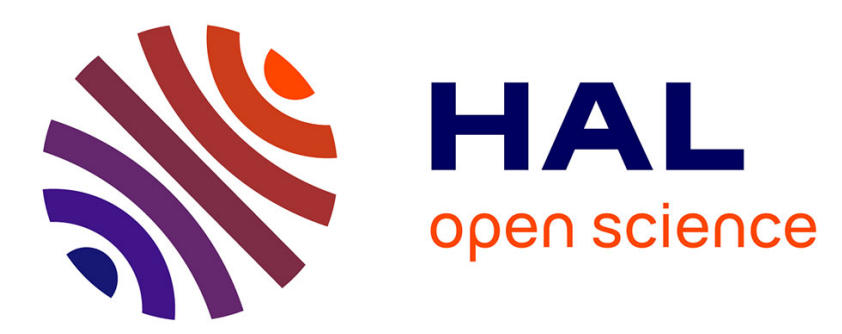

\title{
The expansion of abnormality and the biomedical norm: neonatal screening, prenatal diagnosis and cystic fibrosis in France
}

Joëlle Vailly

\section{- To cite this version:}

Joëlle Vailly. The expansion of abnormality and the biomedical norm: neonatal screening, prenatal diagnosis and cystic fibrosis in France. Social Science and Medicine, 2008, 66 (12), pp.2532-2543. halshs-00661489

\section{HAL Id: halshs-00661489 \\ https://shs.hal.science/halshs-00661489}

Submitted on 12 Nov 2014

HAL is a multi-disciplinary open access archive for the deposit and dissemination of scientific research documents, whether they are published or not. The documents may come from teaching and research institutions in France or abroad, or from public or private research centers.
L'archive ouverte pluridisciplinaire HAL, est destinée au dépôt et à la diffusion de documents scientifiques de niveau recherche, publiés ou non, émanant des établissements d'enseignement et de recherche français ou étrangers, des laboratoires publics ou privés. 


\title{
The expansion of abnormality and the biomedical norm:
}

\section{Neonatal screening, prenatal diagnosis and cystic fibrosis in France}

\author{
Joëlle Vailly*
}

* Inserm, Institut de recherche interdisciplinaire sur les enjeux sociaux (Iris, CNRS, Inserm, EHESS, Université Paris 13), Bobigny, France

This text has been published in: Vailly, J. (2008). The expansion of abnormality and the biomedical norm: neonatal screening, prenatal diagnosis and cystic fibrosis in France, Social Science \& Medicine, 66 (12), 2532-2543.

\begin{abstract}
Developments in biomedicine have remodelled the time-honoured questions of how to define the normal and the connection between the normal and the norm. My work deals with the expansion of the idea of abnormality through a study of the practices involved in neonatal screening for cystic fibrosis in France. It is based on observations made at meetings between paediatricians and geneticists involved in the screening programme, and a seven-month study in a tertiary care centre for cystic fibrosis. On the one hand, the study highlights the technical limitations of screening, which have the effect of expanding biological abnormality. On the other, it deals with the rationales and associated practices used by health care professionals for paediatric monitoring that are behind the expansion of clinical abnormality. Lastly, the consequences of those practices are analysed at the point where neonatal screening and prenatal diagnosis meet, showing how the biomedical norm, with respect to foetuses, is altered. The political and moral space in which this development has occurred is discussed.
\end{abstract}




\section{Introduction}

The unending medical enterprise that consists in distinguishing the normal from the abnormal and the pathological has a long-standing history, which Canguilhem (1978) analyzed in his famous book "The normal and the pathological". As it is usually understood today, the notion of normality can be historically dated. It goes back to the 1820's when Broussais, a French physiologist, offered a novel organic theory of disease according to which pathological phenomena were purely quantitative variations of normal physiological phenomena (Canguilhem, 1978; Hacking, 2006). This idea was a huge success, particularly under the influence of Comte, who shaped it into a vast political design. In Comte's view, for society as a whole to be in a state of normality is an assurance of progress and normality should hence be everyone's goal (Canguilhem, 1978; Hacking, 2006). Clearly, from a very early stage, normal and abnormal phenomena conveyed not only purely factual circumstances, but also an attachment to a value. In other words, they were linked to an ideal state. Generally speaking, this attachment takes place through a shift from the normal to the norm: "The normal is at once the extension and the exhibition of the norm... A norm, a rule, is what can be used to right, to square, to straighten," Canguilhem (1978, pp. 176-177) emphasizes. In the same spirit, Hacking (2005, p. 3) recalls that the idea of normality establishes a bridge between description and evaluation, and that it has two purposes - one, descriptive, the other normative: "It is an idea we ostensibly use for objective descriptions, based on facts... It is also an idea that we use when making value judgments, instituting rules or establishing principles." The separation between the normal and the abnormal is by no means neutral because it contributes to delineating a social and moral space. Using several contemporary examples, such as the "nevra" (nerves) disease of immigrant women in Quebec or 
medicalisation of old age, what Lock (2000) shows is that, far from being merely a product of biological make-up, normality and abnormality are culturally constructed and associated with a social, political and moral order.

In step with the changes occurring in medicine, in the 1960's Canguilhem (1978) supplemented his initial proposition. He began to take into consideration what was then the novel study of genetic mutations, relating them to the concept of error. He uses the following formula to sum up the idea: "To be sick is to have been made false... in the sense of a "false fold" [i.e., wrinkle: faux pli] or a false rhyme." (Canguilhem, 1978, p. 208). Since then, it has been demonstrated that these mutations can help to establish a diagnosis by elucidating the biological basis of the symptoms or by uncovering a major molecular aberration. However, because these mutations are often unable to predict how severe the disease will be or when it will become apparent, they leave open the question of the boundary between the normal and the pathological and, moreover, the associated prognosis (Miller, Ahern, Ogilvie, Giacomini, \& Schwartz, 2005; Rose, 2001; Temple, McLeod, Gallinger, \& Wright, 2001). In addition to their possible intrinsic ambiguity, genetic criteria for diagnostic purposes are sometimes at odds with physiological and biological criteria (Miller, Ahern, Ogilvie et al., 2005), e.g., in the case of leukaemia and lymphoma (Keating \& Cambrosio, 2000). Introducing the notion of biomedical platform, Keating and Cambrosio (2003) describe a process through which the clinic, which scrutinizes the pathological, and the laboratory, which scrutinizes the normal, intermingle and are realigned.

My study revisits these issues that are once more in the limelight. Its object is neonatal screening for cystic fibrosis (NSCF), which was launched in France in 2002 (Vailly, 2006; Vailly, 2007) ${ }^{1}$. This topic was chosen because neonatal screening has taken on considerable proportions in some countries. Some federal states of the United States screen for more than 40, largely genetic diseases at birth (ACMG, 2005). Until recently, NSCF was conducted only 
in France, almost the whole of Australia and New Zealand, and some areas in other countries. Today, many states in the U.S. have implemented the scheme (NNSGRC, 2006), and Great Britain is planning to expand its coverage to the whole country (http://www.newbornscreening-bloodspot.org.uk/). Another feature that makes cystic fibrosis (CF) a worthwhile study topic is that its history has been marked by the question of its boundaries from the beginning. Cystic fibrosis has undergone an overall process of nosological expansion, with the addition of disorders that are defined as being mild forms of $\mathrm{CF}$, such as pancreatitis or congenital bilateral absence of the vas deferens - a form of infertility (Hedgecoe, 2003; Kerr, 2000, 2005). Researchers in social science disagree as to whether this expansion was succeeded by a contraction (due to the subsequent exclusion of congenital bilateral absence of the vas deferens from the CF category) (Hedgecoe, 2003; Kerr, 2005). There is also another debate about whether genetics has played an ascendant or a relative role in this process of reclassification (Hedgecoe, 2003; Kerr, 2005).

My study presents an ethnographic analysis of the biomedical definition of the normal and the abnormal that is at work in the borderline forms of genetic disease in the context of NSCF, and some of that definition's "consequences", construed as its social and moral implications (Bowker \& Star, 2000). The aim of this work is to answer two questions: how does NSCF contribute to the expansion of abnormality? How, in turn, does this expansion alter professional practices? A number of investigations on classification in biomedicine focus on the nosological dimensions and/or professional practices. They rely on an analysis of the biomedical literature (Hedgecoe, 2003; Kerr, 2000), and on interviews (Keating \& Cambrosio, 2000; Kerr, 2005; Miller, Ahern, Ogilvie et al., 2005), or, less frequently, on observations (Featherstone, Latimer, Atkinson et al., 2005). My study, which relies on observations, aims at supplementing these analyses through the scrutiny of professional practices and their implications. What it does not deal with are the consequences of NSCF for 
either the child categorized as suffering from CF or the child's family. In the first part of this text, I look at the technical limitations of NSCF that lead to identifying a substantial rate of so-called borderline forms, whereby the purview of biological abnormality is expanded. The second part deals with the expansion of clinical abnormality. It is rooted in the attitudes adopted by health care professionals, which vary from an individually-based to a standardized approach, and the practices associated with paediatric monitoring. Finally, a local field study is used to analyse the consequences of these practices at the point where neonatal screening and prenatal diagnosis meet, showing how the norm, but this time in respect of foetuses, is altered. The political and moral space in which this development has occurred is discussed.

\section{Study description}

The research method used for the project comprises two complementary components. One component consists in the observations made at 16 meetings on NSCF conducted between June 2003 and May 2005 (symposia, scientific meetings, national congresses, etc.), including all the major national meetings held on the topic. These meetings lasted between $1^{1 / 2}$ and 8 hours (mean duration $3^{1 / 2}$ hours) and their purpose was to provide health care professionals with an opportunity to take stock of techniques and practices used in conjunction with this new screening programme. They were attended by between 15 and 150 health care professionals - mainly paediatricians but also geneticists and biologists - who work in the screening and care centres set up when NSCF was launched, referred to as the CRCMs (French acronym for Cystic Fibrosis Resources and Expertise Centres; Vailly, 2006). In addition but to a lesser extent, representatives of the professional association in charge of organising neonatal screening (Vailly, 2006), called the AFDPHE (the French Association for Screening for and Preventing Handicaps in Children) also took part in these meetings. For the 
purpose of this study, extensive notes, including near-verbatim minutes, were taken during these meetings. These observations were associated with informal discussions I conducted with the participants. The analysis forming the basis for this article was performed as follows: I noted and classified the various occurrences of what was said about the so-called borderline forms of the disease and about related points, such as technical features, the question of naming the disease, an individual case-based versus a standardized approach, care management and prenatal diagnosis. A common method for qualitative surveys was applied that consists in adjusting the analysis while investigations go forward. In this way, theoretical notions can be reformulated and hypotheses are generated (Glaser \& Strauss, 1967). It is similar to the constant comparative method of analysis, inasmuch as it integrates various sources of qualitative information (observations, informal discussions and reviews of documents) for the period under consideration.

The other component of the research method is a qualitative study I conducted in 2005 over a period of seven months in a major Paris hospital. I chose this hospital because it is considered to be a medical and scientific standard of reference for paediatrics and genetics in France. I took part in 91 paediatric consultations and 37 genetic counselling sessions for CF arranged for by the CRCM paediatrics and genetics departments. Willingness to participate and a favourable assessment of participation by the clinical team were the selection criteria for observation. In this centre, consultations in connection with NSCF are not separate from those for cystic fibrosis diagnosed on the basis of symptoms (prior to the implementation of neonatal screening). Out of the 91 paediatric consultations observed, 30 related to children that had been screened (i.e. 12 medical files), and of the 37 genetic counselling sessions, 7 were identified by screening (i.e. 7 medical files). The inclusion criteria called on were selective. They consisted in concentrating on borderline forms detected during neonatal screening for which the full set of data - both paediatric and genetic - was available. Of the 
various families I followed both from the paediatric and genetic standpoints, two met the full range of criteria and could support an in-depth analysis. Extensive notes, including nearverbatim minutes, were taken during the consultations. From these observations and for the purposes of the present study, I extracted the way in which results bordering on normality are dealt with during consultations and how the information is conveyed to the parents.

All observations were performed with the explicit consent of the interested parties: clinicians, organisers of the meetings, parents and children (except infants and toddlers). For the sake of confidentiality, names and surnames of the people involved have been altered. The research ethics committee of the hospital where I performed the study does not evaluate social sciences projects, only biomedical ones. This is consistent with French bioethical laws, which focus on biomedical projects.

\section{Techniques and biological abnormality}

\section{From form of knowledge to definition of abnormality}

Techniques, as has long been shown by researchers in social science, are by no means mere applications of scientific knowledge, free of any social contingencies (Vinck, 1995). Indeed, the NSCF procedure in France is based on three techniques that are associated with different stages in the social history of the disease (Kerr, 2005). It relies first on a blood assay of a protein called immuno-reactive trypsin (IRT) performed on all newborns. If this first test is positive, a commercially available kit is used to detect the 30 most frequent mutations of the CFTR gene involved in the aetiology of the disease. If one or two mutations are found or the trypsin level is above a cut-off value, the families are asked to come to the CRCM to have a sweat chloride test performed on the child (sweat test). Complexity would be relatively constrained if there was no overlap between normal and pathological findings obtained by 
these techniques - an uncommon occurrence in biology (Grimes \& Schulz, 2002) -, and if they produced consistent classification systems. As described further on, each of the three techniques refers to a different form of knowledge that produces its own definition of normality.

The IRT assay arises from statistical knowledge, based on the increase in IRT levels in young people suffering from $\mathrm{CF}$ as compared to a control group. This knowledge is not explanatory, i.e., it does not help us discover the root of the disease because the clinical and biological significance of the IRT level is not known. In spite of its shortcomings, this assay affords the practical benefit of distinguishing the so-called suspect cases from the normal children within the overall population of neonates - but not at this stage between diseased and normal ones. The intervention threshold, which sets up the dividing line between these two categories, is quantitative and defined by the organisers of the screening campaign. They settle on a compromise between sensitivity, that tends to bring the threshold down, and specificity, that tends to raise it. In fact in 2003, the cut-off value was increased on the consideration that the number of children needing genetic investigation was too high (approximately 6000 per year), and that it entailed a considerable financial cost without bringing any added benefit in terms of sensitivity (AFDPHE, 2004). In spite of the higher cutoff value, there are nonetheless still 4000 suspect cases for 170 confirmed cases of cystic fibrosis every year. In short, the definition of abnormality under this first test, notwithstanding the efforts made by screening programme organisers to reach a balance between specificity and sensitivity, is a broad one. If the result of the first test is suspect, a second technique based on molecular testing comes into play.

The second stage is set in a form of knowledge - genetics - that elucidated the primary cause of the disease which is a mutation in a gene that codes for a chloride channel. The reason this test has been included in the screening procedure is that it increases NSCF 
specificity and has thereby helped to make NSCF socially acceptable (Vailly, 2004). Indeed, the number of children detected that carry one or two mutations is brought to approximately 550 as a result of this test, which classifies into three categories: "normal" (no mutation and IRT below cut-off value), "suspect" (one mutation) and "affected" or "likely to be affected" (two mutations). In cases where one or two mutations are detected, the situation is made more complex for two reasons. First, there is the problem of transposing techniques that arises because the tools used were designed for diagnostic rather than screening purposes. In the case of NSCF, the kit used is capable of identifying $80 \%$ of the mutations discovered in France, including some so-called mild mutations which, while helpful in diagnosing adults that show clinical signs, have no clearcut significance in respect of the overall population of newborns. For instance, the mutation referred to as $\mathrm{R} 117 \mathrm{H}$, which turns out to be the second most common mutation in France, indiscriminately entails classic forms of $\mathrm{CF}$, attenuated forms or else simple forms of infertility, or even no symptoms at all. More precisely, R117H leads preferentially to $\mathrm{CF}$ when it is associated with another genetic marker called 5T, and preferentially to infertility when it is associated with the marker called 7T. However, some cases of the 7T association with respiratory symptoms have been reported (Roussey, 2005). The implications of this will become apparent further on. Currently, the R117H mutation represents $8.5 \%$ of the mutations detected in the screened population, whereas before NSCF was implemented, it accounted for only $0.3 \%$ of the mutations in patients on record in tertiary care centres (ONM, 2001). This significant increase probably arises from the fact that some of the children were considered normal before neonatal screening was implemented and therefore eluded mutation incidence statistics. To set these problems in perspective however, it should be noted that some 500 heterozygous newborns (with one mutation) are detected every year, i.e., a few percent of the total population of heterozygotes. The reason for this is that most heterozygotes are classified as normal following the IRT test and are not therefore 
subjected to the genetic test. As a result, the issues raised by the genetic test do not concern all heterozygotes born in France each year.

In addition to the problem of transposing techniques, there is a diversification effect. Indeed, whenever there is uncertainty, the CFTR gene is extensively explored using sophisticated techniques, sometimes leading to the discovery of one of some 1300 different mutations that have been identified in the world. Screening on the scale of a population intensifies this effect of diversification - the broader the population, the higher the probability of isolating rare or ill-known mutations. In other words, as a paediatrician explained at a round table session on NSCF during a national paediatrics congress:

"With the kit and technological breakthroughs [in genetics], the laboratory detects mutations more frequently and the percentage of mild forms has increased" (Paediatrician 1, Observation 12).

In short, with the molecular test, although the definition of abnormality is narrowed as compared with IRT assaying, it is broadened in comparison with criteria which until then had been established on the basis of symptoms, regardless of how mild or severe.

As for the sweat test (ST), it can rely on three quite distinct chloride assaying techniques that will not be described here. It is based on knowledge that is both clinical, tracing back to the physiological causes of the disease, and statistical, showing up higher chloride levels in affected patients than in controls. It leaves the realm of screening and enters into that of diagnosis, performed in the course of paediatric consultations. The associated categories are normal, CF-affected and, as will become clearer further on, potentially an intermediate class whose very existence and denomination are in the balance with NSCF. Differentiating between the normal and the abnormal here relies on quantitative data that generate not a dividing line but rather an indeterminate area that is bounded by two cut-off values. This is a well-known difficulty but one that is aggravated in the case of NSCF by two things. On the one hand, the lower of these two values is contentious in France because there are discussions 
about bringing it down from the initially chosen value of 40 to 30 , so as not to "miss cases". On the other, test results may differ depending on the chloride assaying technique used. This means that the classification is partially built up out of the local context and by the place where the method is used (Roth, 2005). This aspect comes out clearly in this exchange between professionals at a meeting of some dozen paediatricians and biologists from CRCMs organized to provide an overview of borderline forms:

- "We agreed on a lower value of 30" (Biochemist 1).

- "You can't say 30 regardless of the test; my 30 may be different from yours" (Paediatrician 2, Observation 14).

Finally, a borderline result (in the 30/40 - 60 range) should be placed in a local, but also a temporal context. In a presentation given before his peers at a round table session on NSCF at a national paediatrics congress, a paediatrician in charge of the CRCM explained: "With time, borderline sweat test results tend to go positive" (Paediatrician 1, Observation 12). This means that the intermediate ST values may increase and fall into the diseased category. Lowering the cut-off value (for reasons that are examined further on) and projecting into the future in respect of this third test thus expand the idea of abnormality.

\section{Spatial and temporal remodelling of the disease}

The difficulties described above should not give the impression that the situation is one of complete confusion. While the variability of cut-off values and measuring methods makes it difficult to precisely assess the number of borderline cases, the elements recorded during the observations indicate that about one fourth of the neonates categorized as affected are borderline. This implies that although the number of borderline infants concerned is low (170 infants are diagnosed as having cystic fibrosis at birth every year in France), they account for a relatively high proportion of diseased infants. Moreover, if all the centres used the 30 cut-off value, that proportion would increase significantly. 
Overall, the techniques implemented for NSCF lead to classifying more babies in the abnormal category as the outcome of two effects. One is a cumulative effect. In their interpretations, health care professionals do not privilege either molecular testing or the sweat test. This means that, in the eyes of professionals, uncertainties tend to be incremental rather than cancel each other out (elevated IRT plus a borderline sweat test; intermediate sweat test plus a mutation, etc.). The second effect is that the weight of clinical considerations has declined in this approach. Without entering into the debate about the relationships between the clinical approach and new genetic technologies (Latimer, Featherstone, Atkinson et al., 2006), which do not come under the scope of this paper, it is useful to compare this result with those of other studies. Featherstone and her colleagues (Featherstone, Latimer, Atkinson et al., 2005) conclude their analysis of the categorization of cases of dysmorphology (congenital malformations) with the idea that "the "clinic" still asserts its symbolic and functional power: the "gaze" of the clinician and the clinician's warrant of personal knowledge exert their influence". This is only an apparent contradiction with the study presented here providing a distinction is made. In the case of dysmorphology, the extreme variability of the symptoms and of the genetic alterations in all of the chromosomes is such that it is not always possible to establish an association between them. Furthermore, the persons monitored are mostly children or adults that show signs or symptoms that physicians seek to categorize. In the case of NCFS, the severity of the disease is variable but it is associated with a gene that is amenable to analysis, making the genetic approach relatively simpler, even though, as we have seen, the results it yields may be ambiguous. In addition, neonates that are borderline display few or no symptoms, a fact which undermines the clinical approach. As a result, the relative weight of the "clinic" compared to biology and genetics declines during the screening period and the early years of the child's life, albeit perhaps temporarily. Finally, in conclusion to this first part, it should be noted that the decline of 
clinical considerations goes beyond the tension between the clinical aspects and genetic reclassification described by other authors (Hedgecoe, 2003; Miller, Ahern, Ogilvie et al., 2005). In these cases, the process begins for a family when a patient exhibits symptoms of variable severity needing a diagnosis and treatment. The situation is different when the "patient" - but is the term "ill" justifiable? - is still very young and his or her parents have not yet actively sought the advice of a clinician. The conception of disease continues the process of change that was occurring in the $20^{\text {th }}$ century (Kerr, 2005). It is temporally remodelled because the period prior to the symptoms appearing during which people would previously have been considered healthy is now one where they are considered as patients. The conception is also spatially remodelled because families that previously were never considered to be affected now are.

\section{Medical practice and clinical abnormality}

Early treatment in tertiary care centres of CF-affected children was one of the grounds for introducing NSCF in France (Vailly, 2006). However, early treatment that requires admitting very young babies into a demanding care management scheme may be seen, in particular by paediatricians, as questionable when the babies exhibit no symptoms. Health care professionals are however under pressure to respond to these ambivalent situations quickly. What line of reasoning do they call on to take action? How do they classify and manage children whose status is dubious? Just as with other diseases, these practices and the label they generate have some very considerable implications for the individuals concerned because they hugely impact the way others see the person, the person's self-perception, employment prospects, medical cost coverage, etc. (Bowker \& Star, 2000; Temple, McLeod, Gallinger et al., 2001). 


\section{The weight of words}

The first choice that health care professionals must make relates to the name given to the condition and what it implies. The term "pre-CF", offered in biomedical literature (Bush \& Wallis, 2000), was sometimes brought up during the observations, with reference to the situation whereby, as previously noted, a number of normal or borderline STs tend to go positive with time. Although there seems to be a consensus among professionals that the designation does have major consequences, views about these differ. This conversation between professionals recorded at a national meeting that brought together some fifty leading CRCM paediatricians is evocative:

- "Sometimes the term CF is more of a burden than the disease itself..." (Paediatrician 3).

- "Why use a different term as long as you qualify the information?" (Paediatrician 4).

- "With underprivileged people, sooner or later you have to give a yes or no answer" (Paediatrician 5).

- "I take the entirely opposite view. It's all very well to say mild CF..." (Paediatrician 6).

- "Once it has been established that there is no phenotype-genotype [observable feature, severity of the disease-genetic pattern] correlation, I don't see how we can tell them it is not a serious disease..." (Paediatrician 4).

- "It's a different matter if you label it CF when you have good reason to believe that the only problem will be infertility" (Paediatrician 6, Observation 1).

Clearly, these exchanges show up two things. First, they show that health care professionals express their preoccupation with qualifying the information given to parents. They are apprehensive about the concern they stir up in parents and express their discomfort in relation to these situations. Sometimes, they long for the hindsight that will enable them to acquire expertise so that, as the children grow older, they can adjust their practices accordingly. At the time the survey was conducted, no stable national consensus had been achieved. Secondly, these exchanges illustrate the way in which children with a dubious diagnosis will sometimes, on the basis of arguments relating to language, social 
presuppositions or biomedical knowledge, be classified in the generic "CF" category. In 2004, a study conducted by AFDPHE (2004) showed up that a CF diagnosis had been established for 18 children that were homozygous (two identical mutations) or compound heterozygous (two different mutations) for the R117H mutation while having a normal sweat test. These children are not just carriers of a biological anomaly; they have an illness that is generally serious, irrespective of their own particular status. Indeed, all parents in maternity wards are given an information brochure on neonatal screening that specifies: "Cystic fibrosis brings about nutritional disorders and, more critically, a progressive lung disorder that makes it a serious condition." Just as with any disorder, the disease reveals itself through words that include the term $\mathrm{CF}$ (pre-CF, atypical $\mathrm{CF}$, etc.). On the other hand, in contrast with other disorders, it severs the link between words and symptoms and once stated resonates even more cruelly.

\section{«Cases» and statistics}

What is at stake is not just a matter of naming but also the care that will be given to the child. Health care professionals are in two minds about whether to adopt a standardized or individually-based approach. One set of arguments derives from a preliminary assessment of a regional screening programme that was presented at one symposium. This was an early programme that was launched in the 1980s in Brittany, and had the benefit of greater hindsight as compared to the national programme. Twenty-six children with so-called mild mutations subjected to regular medical monitoring were involved. The assessment was that their respiratory status was generally satisfactory with the exception of one child. Along the same lines as this regional programme assessment, a number of AFDPHE officials mention the need to gather statistical data through a national epidemiological data registry. At a meeting attended by the leading CRCM paediatricians, one stresses: "It is important for us to 
have statistics" (Paediatrician 7, Observation 1). On the other hand, paediatricians confronted with uncertainty speak repeatedly of an individual "case-related" approach. This is apparent in these three quotes observed and recorded during national NSCF meetings:

"We had a case of mild mutation where the child died" (Pulmonologist 1, Observation 15).

"At [X], we have an experience with a child that has [an] $\mathrm{R} 117 \mathrm{H}$ [mutation] and is ST negative, while his older brother is ST positive" (Paediatrician 4, Observation $1)$.

"There are cases where patients die even with mild mutations. As a rule, these patients have longer life expectancies, but if they die at the age of 12 or $20 \ldots$ " (Paediatrician 1, Observation 8).

Even though clinicians are aware that death is not the inevitable outcome, they tend to underscore these adverse instances, which leave a more lasting impression, than by favourable outcomes. The negative situations are the ones that are being brought into view. This has practical repercussions because the tendency is to be cautious and unwilling to run the risk of failing to detect situations where a child's condition might suddenly deteriorate. At a meeting on borderline cases of about ten paediatricians and biologists from CRCMs, one paediatrician explained to a colleague:

"American investigations have shown that with a [ST] cut-off value of 40, there is a non-negligible risk of missing some children. We cannot allow that to happen; 5 or 6 years from now, it may be up to 59 or 63" (Paediatrician 2, Observation 14).

These precautions mean that a great majority of health care professionals prefer to monitor children that have borderline forms, generally under a more flexible regimen than the one applied to classic CF forms, rather than consider them healthy. On the national scale, a preliminary study conducted by the clinicians themselves in 2005 shows that when a child had two mutations, one of which was mild, he or she was monitored every month or every three months. When a child had two classical mutations and a borderline ST, he or she was monitored every month. When a child had no or one mutation and a borderline ST, one third 
of health care professionals reassured parents, while two thirds asked families to come back and did not reach a firm conclusion at that stage (Observation 14).

When they make their initial assessments, paediatricians assemble their own local resources which may later be used as guides for classification (Roth, 2005). Along the same line of thought, the organisers of screening schemes call for statistics they hope will bring up the level of generality. Specifically, "sciences that classify people" must be able to "count" and produce the quantitative data most suitable to effective classification (Hacking, 2005). But, as we have already seen, genetic mutations are not well-suited to this exercise, and the cases of adverse progression of the disease within the cohorts arouse doubts and induce health care professionals to take a cautious approach. The tension that exists between assessments of entire populations and the starkness of cases is apparently tending to move in favour of the latter. Specifically, the approach to child monitoring both derives and deviates from two medical traditions (Desrosières, 2000). It no longer confines itself strictly to the "one-to-one interaction" (colloque singulier) between the patient and physician, whereby the medical supervision focuses exclusively on the individual case. On the other hand, it is not content with statistics based on averages that miss particular situations. More in keeping with Claude Bernard's experimental medicine, the preference is for a medicine that claims to be both scientific and distrustful of probabilities. This generates a situation where statistics appear to be case-driven. In other words, it is as if the whole group whose future is uncertain was under the influence of what is actually happening to the individual patient. In spite of the fact that care management for borderline forms is less demanding than for classic $\mathrm{CF}$ - in the latter case, the average daily time spent on care is two hours (personal observations) -, abnormality is expanding its influence on clinical practice in the area of consultations and physiotherapies.

Furthermore, as will become clear further on, this affects not just screened children. It reaches beyond the birth stage to foetuses. Although some questions had begun to arise about 
what should be done in this respect, this point was not as frequently discussed during the first observations, because NSCF had recently been introduced and the number of pregnancies subject to prenatal testing was still small. The purpose of my local study was to gain a better grasp of the implications of this linkage between the definition of the normal and the establishment of a medical norm.

\section{From the normal to the norm}

\section{Two enlightening situations}

Situation 1: Catherine and Patrick are the parents of little Lea who was born a month and a half ago. The future appears rosy until Professor Berteau, Head of the Paediatrics Ward in the hospital where I conducted my study phones them to discuss " taking a trypsin level test" on the baby, and arranges for an urgent appointment the next day. The next day, the physician explains that Lea "has two positive indications - a very high trypsin level and the presence of a mutation - but that there must be three [for her to be considered diseased]." Two hours later, on the basis of the sweat test result, Professor Berteau says the test is negative since the value is 25 whereas the norm is 60 and adds, saying every word quite distinctly: "You can definitely assume that your child does not have CF." The parents give a sigh of relief and everything appears to go back to normal. But then the professor suggests that the parents return two months later to check the trypsin level which is decidedly very high (1200 as compared to a cut-off value of 65) and another sweat test, as only one of the two methods usually performed could be interpreted that day. He also urges them to arrange for genetic counselling. Two months later, the parents tell the geneticist that Lea is healthy and her weight gain curve is normal, that the final sweat test is 30 but her trypsin level is still high. The geneticist suggests performing a test to identify which of the two parents is carrier of the identified mutation and 
conduct a thorough exploration of the gene involved so as to detect a possible second, more rare mutation in the child. He adds: "Assuming that she has some form of CF, it would be a very mild one... The sweat test is normal, so in principle there is a low risk of CF as such, but possibly other genetic anomalies, although I think that is very unlikely, which could lead to pancreatitis." Six months later, genetic exploration continues, there have been multiple consultations and tests, the parents are crushed by uncertainty and a conclusion has yet to be reached.

Two months later, once my field study was over, the parents received a letter from the paediatrician informing them that a second, very rare, mutation had been detected in Lea's DNA, saying that the child suffers, "strictly speaking", from "atypical CF". The letter points out that only two cases of this mutation have ever been described by the literature worldwide: one of which involved a male who just had a form of infertility, and the other was a female child who had a form of chronic pancreatitis. Nearly three months later, the geneticist told me that Catherine was two and a half months pregnant and had just undergone a prenatal diagnostic test to check the genetic status of the foetus in respect of those two mutations. He continues saying: "I was careful. There are no signs in Lea, but we cannot guarantee that will remain the case in the future." A week later, we learn that the foetus is healthy and the question of terminating the pregnancy does not come up. Catherine speaks to me saying: "What was clearly stated [in the consultation], was that the decision was ours... but that we were strongly urged to have the prenatal test performed. [The arguments were] that since we have the technical means to identify the foetus's genetic profile, it would be a pity not to do so, knowing there was a risk [of miscarriage due to the sampling operation], quite a low one, I think it was $1 \% \ldots$ and the second argument was that I'm fairly young and if the worst comes to the worst we could always consider another pregnancy." Thirteen months had by then gone by since Lea was born. 
Situation 2: Bastien and Isabelle are the parents of little Zoe, who was given a sweat test according to the same procedure used for Lea, after a positive IRT level result and detection of a mutation - the famous so-called mild $\mathrm{R} 117 \mathrm{H}$ mutation - were discovered during neonatal screening. Very fortunately, the test result (8) was clearly negative and the baby was classified as not affected. A little later, Isabelle and Bastien went to a geneticist to find out whether the mutation was on the maternal or the paternal side so as to be able to warn their respective brothers and sisters in case they wanted to have children. A few months later, Bastien received a letter from the geneticist stating: "The molecular testing conducted on your DNA... shows that you are a carrier of the R117H mutation (associated with alleles 7T, 7T of intron 8)... We advise you to inform your brother that there is a 1 in 2 risk that he is also the carrier of this mutation so that he can seek the advice of geneticist if he so wishes... On the basis of this information... the risk of you and your mate having a child with CF can be estimated to be in the order of $1 / 640$, i.e. a level close to that of the population at large." The way in which the consultation is conducted and the method for calculating the risk of CF are the same as for any other mutation of the CFTR gene, independently of the fact that this mutation, associated with the $7 \mathrm{~T}$ allele, as previously explained, most often produces infertility alone. The genetic profile is therefore clearly included in the "CF" category.

\section{The genetic meeting point}

The two examples provided above underpin the previously described results about the expansion of abnormality occurring with NSCF. They furthermore are instructive as to what is at stake in the borderline cases, where a population-wide neonatal screening scheme intersects with prenatal diagnosis. While the latter is more personalised, the two are linked. The two situations described clearly show that when a mutation detected during neonatal screening is poorly known or mostly associated with a benign form, and very rarely with a 
classic form, prenatal diagnosis is offered for subsequent pregnancies. Clearly, while uncertainty is a long-standing feature of medicine, and indeed inherent to clinical activity, scientific and technical changes alter its contours and fuel it (Fox, 2000). In fact, in this particular centre, the only situations that are excluded from prenatal diagnosis are those where it can be asserted with certainty that the genetic profile will produce only infertility, because geneticists do not consider infertility as medical grounds for terminating a pregnancy. This threshold of acceptability is confirmed by observations made at genetic counselling sessions during which a finding of an infertility-associated genetic profile was treated as normal. In fact, practices are equally determined by the severity of the disease and the notion of certainty. In practical terms, this means that infertility as such is not defined as a form of CF whereas pancreatitis is; only ascertained infertility is separated from the other disorders. CF and infertility are treated differently in terms of the ethical grounds for performing prenatal diagnosis inasmuch as genetics provides a "guarantee". In contrast, CF, pancreatitis and infertility join up at a genetic meeting point when a given mutation is liable to be present, even if only sporadically. This is where the shift from normal to norm mentioned in the introduction occurs. It is where the expansion of abnormality is embodied by the expansion of the faculty for selection, which may affect other members of the family (uncles, aunts, etc. with the same mild mutation). As with the paediatricians, these practices are sometimes questioned by the very people who implement them. One of the three geneticists surveyed in the centre told me during a conversation I had with him concerning borderline forms:

"Whenever a mutation is found [by neonatal screening], even the R117H, people are sent to genetic counselling.... That's the way it is, the machinery is in motion whether or not it is justified, I don't know [he sighs]. I don't know... The uncles, aunts, cousins, they all consult" (Geneticist 1).

These results are an encouragement to pursue investigations from the standpoint of parents and on practices relating to pregnancy terminations on medical grounds. One instance 
that supports this remark is a short article published in the "New Scientist" in 2003 describing pregnancy terminations in the United States on the basis of non-pathogenic polymorphism detected by commercial kits that were confused with the CFTR gene mutations (Concar, 2003).

\section{Conclusion}

\section{A more general expansion}

Various studies indicate there is an expansion of medical abnormality in the Western countries. This is illustrated by categories such as: the "overweight" where the associated Body Mass Index has been lowered (Hacking, 2005); autism, whose enlarged definition produces more core and more related cases (Hacking, 2005); lead poisoning, associated with a lowered acceptable lead level in the blood thus turning a rare disease into an epidemic (Fassin, 2004). More generally, screening of the whole population or the so-called "risk" population (Armstrong, 1995; Van Hoyweghen, Horstman, \& Schepers, 2006), broadening the scope of mental health (Castel, 1981; Lock, 2000), the increasing sensitivity of biomedical techniques (Getz \& Kirkengen, 2003; Kaufert, 2000) are all instrumental in bringing about this expansion. This powerful movement is only slightly disrupted by the major social and economic disparities that prevent certain populations from having access to health care and result in a conception of medical abnormality applicable to the latter that is more restricted (Khoshnood, De Vigan, Vodovar, Bréard, Goffinet, \& Blondel, 2006; Markovic, Manderson, \& Quinn, 2004). On the whole, it is quite apparent that biomedicine can increasingly avail itself of techniques capable of uncovering and managing deviants. Today what is central is not to find out whether the abnormal can be distinguished from the normal by qualitative, quantitative factors, or a combination of both, which was Canguilhem's starting point (1978). 
It is rather, as Canguilhem himself outlined, to attempt to understand how this expansion and the values of our societies interrelate. As noted by Fassin and Bourdelais (2005), bringing down the detection and tolerance thresholds for diseases is part of a broad, albeit very unequally distributed, movement that rejects bodily impairment, a condition that is increasingly considered intolerable. Neonatal screening indeed exemplifies one way in which these levels are lowered.

\section{The space of neonatal screening}

My study relates to a given space and time and as such does not presume upon future developments in the area of neonatal screening, nor of practices in centres other than the one where it was conducted, although it is interesting to note that the latter is credited with a high level of scientific and medical legitimacy. It does however provide two pieces of information. First, it shows how the idea of abnormality is expanding with NSCF, proceeding from its concomitant use of three approaches: a technologization of medicine, a preventive policy geared at the whole population, along with clinical practices geared to the individual. The use of a commercial kit makes no small contribution to this process by facilitating matters materially and hence permitting entire populations to be screened. At a time when other techniques that would make mass genetic testing possible such as "DNA chips" are being developed (HGC, 2005), a conjunction is occurring between totalizing procedures (population screening) and individually-based techniques (medical consultations and genetic counselling). Second, my study shows that by bringing borderline forms into view, neonatal screening can lead to expansion through prenatal diagnosis. Of course, prenatal diagnosis for mutations referred to as mild may occur from time to time independently from NSCF, but the screening programme amplifies the phenomenon. 
Genetic counselling has been the topic of many publications in the social sciences, because of the social and ethical issues these new techniques raise, especially genetic technologies (Dusart, 1995; Ettore, 2000; Rapp, 1999; Remennick, 2006; Williams, 2006). But so far, genetic counselling has not been investigated at the point where the neonatal and the prenatal approaches meet. In one respect, current knowledge enables children, who in many cases are or will be severely affected, to be screened and monitored at birth. Furthermore, once a first child was screened at birth and found to be affected, this knowledge makes it possible to avoid sibships with several CF-affected members through prenatal screening of any subsequent pregnancy. In another respect, to paraphrase Foucault (1994), there appears to be a price to pay $^{3}$. The price paid is to pronounce foetuses that have good chances of not getting $\mathrm{CF}$ to be suspect or even undesirable. Whether the price is low or high is not discussed here, the intention not being to be prescriptive or "normative". But the political and moral space in which this development has occurred is worthy of note.

Indeed, NSCF has a particular contour: while it is deeply rooted in the compassionate and socially acceptable care that must be given to sick children, it does not offer adequate treatment possibilities that would make a prenatal diagnosis redundant. The prenatal diagnosis it proposes under these circumstances is clearly distinguishable from the usual prenatal diagnosis, which is offered on the basis that there is an affected person in the family. It is also clearly distinguishable from systematic heterozygote screening among adults that raises controversy about actual or supposed eugenics (Gayon \& Jacobi, 2006; Paul, 1994). The shift in the norm occurring here is located in a new political and moral space compared to these other two configurations. On the one hand, it is both individual (sick persons, "suspect" cases and their families are given paediatric advice and genetic counselling) and collective (from the outset, the whole population is targeted). On the other, NSCF is ethically relatively consensual because it is usually offered in connection with neonatal screening and hence 
targeted at sick children. Let us wager that if genetic tests continue their advance, this space will receive the attention of social scientists investigating the politics of biomedicine.

\section{References}

ACMG (2005). Newborn screening: toward a uniform screening panel and system. Report of the American College of Medical Genetics.

AFDPHE (2004). Le dépistage néonatal de la mucoviscidose en France. Statistiques nationales 2002-2003. La Dépêche (n50).

Armstrong, D. (1995). The rise of surveillance medicine. Sociology of Health \& Illness, 17(3), 393-404.

Bowker, G.C., \& Star, S.L. (2000). Sorting things out. Classification and its consequences. Cambridge, London: The MIT Press.

Bush, A., \& Wallis, C. (2000). Time to think again - cystic fibrosis, like cancer, is not an "all or none" disease. Pediatric pulmonology, 30(2), 139-144.

Canguilhem, G. (1978). Le normal et le pathologique. Paris: Presses Universitaires de France (first edition 1966).

Castel, R. (1981). La gestion des risques: de l'anti-psychiatrie à l'après-psychanalyse. Paris: Les Editions de Minuit.

Desrosières, A. (2000). La politique des grands nombres. Histoire de la raison statistique. Paris: La Découverte.

Dusart, A. (1995). La détection des anomalies foetales: analyse sociologique. Paris: Editions du CTNERHI.

Ettore, E. (2000). Reproductive genetics, gender and the body: "Please doctor, may I have a normal baby?". Sociology, 34(3), 403-420. 
Fassin, D. (2004). Public health as culture. The social construction of the childhood lead poisoning epidemic in France. British Medical Bulletin, 69, 167-177.

Fassin, D., \& Bourdelais, P. (Dirs.) (2005). Les constructions de l'intolérable. Etudes d'anthropologie et d'histoire sur les frontières de l'espace moral. Paris: La Découverte.

Featherstone, K., Latimer, J., Atkinson, P., Pilz, D.T., \& Clarke, A. (2005). Dysmorphology and the spectacle of the clinic. Sociology of Health \& Illness, 27(5), 551-574.

Foucault, M. (1994). Dits et écrits II, 1976-1988. Paris: Gallimard.

Fox, R.C. (2000). Medical uncertainty revisited. In G.L. Albrecht, R. Fitzpatrick, \& S.C. Scrimshaw (Eds.), The handbook of social studies in health and medicine (pp. 259276). London, Thousand Oaks, New Delhi: SAGE.

Gayon, J., \& Jacobi, D. (Dirs.) (2006). L'éternel retour de l'eugénisme. Paris: Presses Universitaires de France.

Getz, L., \& Kirkengen, A.L. (2003). Ultrasound screening in pregnancy: advancing technology, soft markers for fetal chromosomal aberrations, and unackowledged ethical dilemmas. Social Science \& Medicine, 56(10), 2045-2057.

Glaser, B., \& Strauss, A. (1967). The discovery of grounded theory. London: Aldine.

Grimes, D.A., \& Schulz, K.F. (2002). Uses and abuses of screening tests. Lancet, 359(9309), 881-884.

Hacking, I. (2005). Seminar "Façonner les gens". Collège de France, Paris.

Hacking, I. (2006). The taming of chance. New York: Cambridge University Press (first edition 1990).

Hedgecoe, A.M. (2003). Expansion and uncertainty: cystic fibrosis, classification and genetics. Sociology of Health \& Illness, 25(1), 50-70. 
HGC (2005). Profiling the newborn: a prospective gene technology? Report from a Joint Working Group of the Human Genetics Commission and the UK National Screening Committee.

Kaufert, P.A. (2000). Screening the body: the pap smear and the mammogram. In M. Lock, A. Young, \& A. Cambrosio (Eds.), Living and working with the new medical technologies. Intersections of inquiry (pp. 165-183). Cambridge: Cambridge University Press.

Keating, P., \& Cambrosio, A. (2000). "Real compared to what?": diagnosis leukemias and lymphomas. In M. Lock, A. Young, \& A. Cambrosio (Eds.), Living and working with the new medical technologies. Intersections of inquiry (pp. 103-134). Cambridge: Cambridge University Press.

Keating, P., \& Cambrosio, A. (2003). Biomedical platforms: realigning the normal and the pathological in late twentieth-century medicine. Cambridge: MIT Press.

Kerr, A. (2000). (Re)constructing genetic disease: The clinical continuum between cystic fibrosis and male infertility. Social Studies of Science, 30(6), 847-894.

Kerr, A. (2005). Understanding genetic disease in a socio-historical context: a case-study of cystic fibrosis. Sociology of Health \& Illness, 27(7), 873-896.

Khoshnood, B., De Vigan, C., Vodovar, V., Bréard, G., Goffinet, F., \& Blondel, B. (2006). Advances in medical technology and creation of disparities: the case of Down syndrome. American Journal of Public Health, 96(12), 2139-2144.

Latimer, J., Featherstone, K., Atkinson, P., Clarke, A., Pilz, D.T., \& Shaw, A. (2006). Rebirthing the clinic. The interaction of clinical judgment and genetic technology in the production of medical science. Science, Technology \& Human Values, 31(5), 599630. 
Lock, M. (2000). Accounting for disease and distress: morals of the normal and abnormal. In G.L. Albrecht, R. Fitzpatrick, \& S.C. Scrimshaw (Eds.), The handbook of social studies in health and medicine (pp. 259-276). London, Thousand Oaks, New Delhi: SAGE.

Markovic, M., Manderson, L., \& Quinn, M. (2004). Embodied changes and the search for gynecological cancer diagnosis. Medical Anthropology Quarterly, 18(3), 376-396.

Miller, F.A., Ahern, C., Ogilvie, J., Giacomini, M., \& Schwartz, L. (2005). Ruling in and ruling out: implications of molecular genetic diagnosis for disease classification. Social Science and Medicine, 61(12), 2536-2545.

NNSGRC (2006). U.S. National Screening Status Report (National Newborn Screening and Genetics Resource Center).

ONM (2001). Rapport sur la situation de la mucoviscidose en 1999. Paris: Observatoire national de la mucoviscidose (Institut national d'études démographiques, Vaincre la mucoviscidose).

Paul, D.B. (1994). Is Human Genetics Disguised Eugenics? In F.W. Robert, C.L. Susan, \& E. Fales (Eds.), Genes and human self-knowledge: historical and philosophical reflections on modern genetics (pp. 67-83). Iowa City: University of Iowa Press.

Rapp, R. (1999). Testing the women, testing the foetus: the social impact of amniocentesis in America. New York: Routledge.

Remennick, L. (2006). The quest for the perfect baby: why do Israeli women seek prenatal genetic testing? Sociology of Health \& Illness, 28(1), 21-53.

Rose, N. (2001). The politics of life itself. Theory, Culture \& Society, 18(6), 1-30.

Roth, W.-M. (2005). Making classification (at) work: ordering practices in science. Social Studies of Science, 35(4), 581-621. 
Temple, L.K.F., McLeod, R.S., Gallinger, S., \& Wright, J.G. (2001). Defining disease in the genomic era. Science, 293(5531), 707-708.

Vailly, J. (2004). Une politique de santé "a priori": le dépistage néonatal de la mucoviscidose en Bretagne. Sciences Sociales et Santé, 22(4), 35-60.

Vailly, J. (2006). Genetic screening as a technique of government: the case of neonatal screening for cystic fibrosis in France. Social Science \& Medicine, 63(12), 3092-3101.

Vailly, J. (2007). Dépister les nouveau-nés : évolutions, débats et consensus. Médecine / Sciences, 23(3), 323-326.

Van Hoyweghen, I., Horstman, K., \& Schepers, R. (2006). Making the normal deviant: the introduction of predictive medicine in life insurance. Social Science \& Medicine, 63(5), 1225-1235.

Vinck, D. (1995). Sociologie des sciences. Paris: Armand Colin.

Williams, C. (2006). Dilemmas in fetal medicine: premature application of technology or responding to women's choice? Sociology of Health \& Illness, 28(1), 1-20.

\section{Notes}

${ }^{1}$ Cystic fibrosis (CF) is mainly characterized by respiratory and digestive disorders. Their severity is highly variable and and difficult to predict. The life expectancy for people suffering from CF is approximately 39 years in France.

${ }^{2}$ The day following delivery, an information brochure called " 3 days old - the age for screening", published by AFDPHE, is handed out to mothers in maternity wards.

${ }^{3}$ Following on from Canguilhem, the question of the consequences of a dividing line between normal and abnormal drawn by the medical knowledge of a given time, was raised in his day by Foucault (1994, pp. 12611262): "What is the price for problematizing and analyzing... what the living subject is...?", "What is the price the subject must pay in order to speak the truth about himself as a madman? The price of constituting the madman as the absolute Other...". 